\title{
Impaired stroke volume and aerobic capacity in female adolescents with type 1 and type 2 diabetes mellitus
}

\author{
S. Gusso • P. Hofman • S. Lalande • W. Cutfield • \\ E. Robinson • J. C. Baldi
}

Received: 11 February 2008 / Accepted: 25 March 2008 / Published online: 30 April 2008

(C) Springer-Verlag 2008

\begin{abstract}
Aim/hypothesis This study was designed to determine whether type 2 diabetic adolescents have reduced aerobic capacity and to investigate the role of cardiac output and arteriovenous oxygen difference $\left(\mathrm{a}-\mathrm{vO}_{2}\right)$ in their exercise response.

Methods Female adolescents (age 12-18 years) with type 2 diabetes mellitus $(n=8)$ and type 1 diabetes mellitus $(n=12)$ and obese $(n=10)$ and non-obese $(n=10)$ non-diabetic controls were recruited for this study. Baseline data included maximal aerobic capacity (cycle ergometer) and body composition. Cardiac output and $\mathrm{a}-\mathrm{vO}_{2}$ were determined at rest and during submaximal exercise.

Results Diabetic groups had lower aerobic capacity than nondiabetic groups $(p<0.05)$. Adolescents with type 2 diabetes had lower aerobic capacity than the type 1 diabetic group. Maximal heart rate was lower in the type 2 diabetic group ( $p$ $<0.05$ ). Exercise stroke volume was $30-40 \%$ lower at 100
\end{abstract}

S. Gusso $(\bowtie) \cdot$ P. Hofman $\cdot$ W. Cutfield

Liggins Institute, University of Auckland,

2-6 Park Ave, Grafton,

Private Bag 92019 Auckland, New Zealand

e-mail: s.gusso@auckland.ac.nz

S. Gusso $\cdot$ S. Lalande $\cdot$ J. C. Baldi

Department of Sport and Exercise Science,

University of Auckland,

Auckland, New Zealand

E. Robinson

Department of Epidemiology and Biostatistics,

University of Auckland,

Auckland, New Zealand

J. C. Baldi

Department of Biological Sciences, Northern Arizona University,

Flagstaff, AZ, USA and 120 beats per $\mathrm{min}$ in the diabetic than in the nondiabetic groups $(p<0.05)$. The $\mathrm{a}-\mathrm{vO}_{2}$ value was not different in any condition.

Conclusions and interpretation Type 2 diabetic adolescents have reduced aerobic capacity and reduced heart rate response to maximal exercise. Furthermore, type 2 and type 1 diabetic adolescent girls have a blunted exercise stroke volume response compared with non-diabetic controls. Central rather than peripheral mechanisms contribute to the reduced aerobic capacity in diabetic adolescents. Although of short duration, type 2 diabetes in adolescence is already affecting cardiovascular function in adolescents.

Keywords Adolescents · Aerobic capacity - Stroke volume . Type 1 diabetes mellitus · Type 2 diabetes mellitus

\author{
Abbreviations \\ $\mathrm{a}-\mathrm{vO}_{2}$ arteriovenous oxygen difference \\ $\dot{V} \mathrm{O}_{2} \quad$ aerobic capacity (volume of oxygen consumed)
}

\section{Introduction}

Type 2 diabetes mellitus is becoming increasingly recognised in adolescents as a result of the rising prevalence of obesity, particularly in girls [1]. Although many recognised consequences of diabetes in adults have been studied extensively, little is known about the effect of type 2 diabetes mellitus on the cardiovascular function of adolescents as this has traditionally been an adult disease [2]. A recent report suggests that adolescents with type 2 diabetes mellitus have lower maximal aerobic capacity compared with non-diabetic adolescents [3] and reduced exercise tolerance compared with adolescents with type 1 diabetes [4]. However, there 
are limited data on cardiac function, in particular cardiac output and stroke volume, and the relative contributions of central (cardiac) and peripheral cardiovascular impairment on exercise capacity in adolescent diabetic patients remain unclear. Therefore we aimed to determine whether central or peripheral mechanisms contributed to lower aerobic capacity in diabetic adolescents. To achieve this, we compared aerobic capacity (volume of oxygen consumed; $\dot{V} \mathrm{O}_{2}$ ), cardiac output and the arteriovenous oxygen difference $\left(\mathrm{a}-\mathrm{vO}_{2}\right)$ at rest and during exercise in four groups of female adolescents (12-18 years): (1) type 2 diabetes mellitus ( $n=$ $8)$; (2) type 1 diabetes mellitus $(n=12)$; (3) obese nondiabetic controls $(n=10)$; and (4) non-obese $(n=10)$ nondiabetic controls.

\section{Methods}

Baseline data included $\mathrm{HbA}_{1 \mathrm{c}}$, body composition determined by dual-energy X-ray absorptiometry (Lunar Prodigy; GE Healthcare, Madison, WI, USA) and maximal oxygen consumption $\left(\dot{V} \mathrm{O}_{2 \max }\right)$ assessed using an electronically braked cycle ergometer (Schiller, Baar, Switzerland). Cardiac output, $\mathrm{a}-\mathrm{vO}_{2}$ and stroke volume were then determined at rest and during submaximal exercise using $\mathrm{CO}_{2}$ rebreathing (equilibration method) [5]. To eliminate the potentially confounding effects of heart rate on stroke volume, measurements were taken at rest and while participants pedalled at workloads that elicited heart rates of 100 and 120 beats per min. None of the participants had diabetic complications or coexisting cardiovascular disease.
The non-diabetic adolescents groups were selected to have distributions of body fat percentage similar to those of the diabetic groups to control for the independent effect of body composition. This study was approved by the Northern Y Regional Ethics Committee, Ministry of Health, New Zealand, and all participants under 16 years of age had parental consent to participate in the study.

Statistical analyses Baseline group comparisons were performed by ANOVA. The maximal exercise response was examined using linear regression models. Haemodynamic responses to exercise over time were compared using linear mixed models for repeated measures. $\mathrm{HbA}_{1 \mathrm{c}}$ and body fat percentage were included in these models and differences between the two diabetic groups and between diabetic and non-diabetic adolescents were tested using a priori contrasts. Significant interactions between time and group in cardiac output and stroke volume were further investigated using ANOVA and post hoc Tukey multiple comparison tests at the three time points. Data were analysed using standard statistical software (SPSS, Chicago, IL, USA; SAS, Cary, NC, USA).

\section{Results}

Group characteristics and responses to maximal exercise are summarised in Table 1. The type 2 diabetic group had lower maximal aerobic capacity and heart rate than the type 1 diabetic group $(p<0.05)$. In addition, aerobic capacity indexed for fat-free mass $\left(\mathrm{ml}\left[\mathrm{kg} \mathrm{FFM}^{-1}\right] \mathrm{min}^{-1}\right)$ was higher in the

Table 1 Participant's characteristics and maximal exercise response

\begin{tabular}{|c|c|c|c|c|c|c|c|}
\hline & \multirow{2}{*}{$\begin{array}{l}\text { Type } 2 \\
\text { diabetes }\end{array}$} & \multirow{2}{*}{$\begin{array}{l}\text { Obese } \\
\text { controls }\end{array}$} & \multirow{2}{*}{$\begin{array}{l}\text { Type } 1 \\
\text { diabetes }\end{array}$} & \multirow{2}{*}{$\begin{array}{l}\text { Non-obese } \\
\text { controls }\end{array}$} & \multicolumn{3}{|l|}{$p$ value } \\
\hline & & & & & Overall & $\begin{array}{l}\text { Type } 1 \text { vs type } 2 \\
\text { diabetes }\end{array}$ & $\begin{array}{l}\text { Diabetes vs non- } \\
\text { diabetes }\end{array}$ \\
\hline$n$ & 8 & 10 & 12 & 10 & & & \\
\hline Age (years) & $14.9 \pm 0.5$ & $15.2 \pm 0.4$ & $15.4 \pm 0.4$ & $15.1 \pm 0.4$ & 0.82 & 0.35 & 0.99 \\
\hline Diabetes duration (years) & $2.5 \pm 1$ & - & $6.1 \pm 3$ & - & $<0.001$ & - & - \\
\hline Height (m) & $1.67 \pm 0.02$ & $1.64 \pm 0.02$ & $1.63 \pm 0.02$ & $1.64 \pm 0.02$ & 0.64 & 0.25 & 0.53 \\
\hline Weight $\left(\mathrm{kg}^{2}\right)$ & $107.2 \pm 5.1$ & $83.1 \pm 4.6$ & $64.7 \pm 4.2$ & $57.8 \pm 4.6$ & $<0.001$ & $<0.001$ & 0.62 \\
\hline BMI $\left(\mathrm{kg} / \mathrm{m}^{2}\right)$ & $38.3 \pm 1.8$ & $31.1 \pm 1.6$ & $24.2 \pm 1.4$ & $21.6 \pm 1.6$ & $<0.001$ & $<0.001$ & 0.94 \\
\hline Body fat $(\%)$ & $44.7 \pm 2.2$ & $43.6 \pm 2.0$ & $34.6 \pm 1.8$ & $28.9 \pm 2.0$ & $<0.001$ & 0.002 & 0.12 \\
\hline Fat-free mass (kg) & $59.8 \pm 2.5$ & $48.4 \pm 2.3$ & $42.5 \pm 2.1$ & $41.6 \pm 2.3$ & $<0.001$ & $<0.001$ & 0.33 \\
\hline $\mathrm{HbA}_{1 \mathrm{c}}(\%)$ & $8.2 \pm 0.4$ & $5.0 \pm 0.4$ & $8.8 \pm 0.3$ & $5.2 \pm 0.4$ & $<0.001$ & 0.27 & $<0.001$ \\
\hline $\begin{array}{l}\text { Maximal heart rate (beats } \\
\text { per min) }\end{array}$ & $172 \pm 3.8$ & $186 \pm 4.0$ & $189 \pm 3.8$ & $198 \pm 3.9$ & 0.001 & 0.002 & 0.04 \\
\hline \multicolumn{8}{|l|}{$\dot{V} \mathrm{O}_{2 \max }$} \\
\hline $\mathrm{ml} \mathrm{kg}{ }^{-1} \min ^{-1}$ & $20.3 \pm 2.0$ & $24.9 \pm 2.0$ & $31.6 \pm 2.0$ & $38.1 \pm 1.9$ & $<0.001$ & $<0.001$ & 0.06 \\
\hline $\mathrm{ml}\left(\mathrm{kg} \mathrm{FFM}^{-1}\right) \min ^{-1}$ & $35.6 \pm 2.4$ & $43.1 \pm 2.4$ & $46.7 \pm 2.4$ & $53.1 \pm 2.3$ & $<0.001$ & $<0.001$ & 0.05 \\
\hline Maximal power (W) & $158 \pm 11$ & $154 \pm 12$ & $161 \pm 12$ & $154 \pm 12$ & 0.98 & 0.85 & 0.73 \\
\hline
\end{tabular}

Data are mean $\pm \mathrm{SE}$ 
non-diabetic groups than in the diabetic groups $(p<0.05)$. $\mathrm{HbA}_{1 \mathrm{c}}$ and diabetes duration did not affect maximal exercise outcomes. Figure 1 illustrates resting and submaximal exercise haemodynamic response. Cardiac output $(1 / \mathrm{min})$ and stroke volume $(\mathrm{ml})$ were lower at rest and during submaximal exercise in the type 1 diabetic group than in all other groups $(p<0.01)$ and higher at 120 beats per min in the obese group compared with all other groups $(p<0.01)$. Cardiac output $(1 / \mathrm{min})$ increased more in the non-diabetic groups than in the diabetic groups in response to submaximal exercise $(p<$ 0.001 ). The changes in cardiac output and stroke volume in response to exercise (over time) in the diabetic groups were similar ( $p=0.1$ and $p=0.2$ respectively). Cardiac output and stroke volume were then indexed to fat-free mass $\left(\mathrm{CO}_{\mathrm{ffm}}\right.$ and $\mathrm{SV}_{\text {ffm }}$ respectively) in order to account for group differences in body composition. The $\mathrm{CO}_{\text {ffm }}$ and $\mathrm{SV}_{\text {ffm }}$ responses to submaximal exercise were $30-40 \%$ lower in both type 1 and
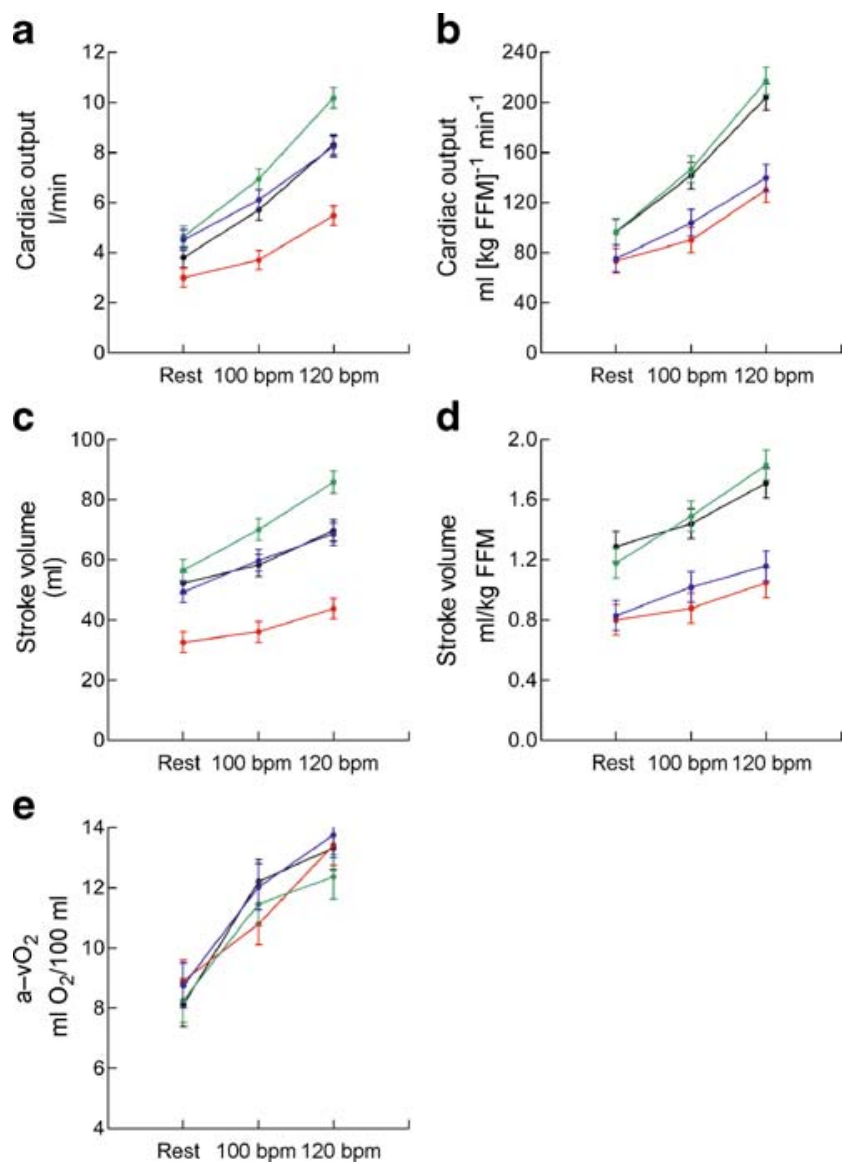

Fig. 1 Haemodynamic data. Cardiac output (a, b), stroke volume (c, d) and $\mathrm{a}-\mathrm{vO}_{2}$ (e) in type 2 diabetes mellitus (blue), type 1 diabetes mellitus (red), obese non-diabetic (green) and non-obese non-diabetic (black) adolescents. $p<0.05$ type 1 vs type 2 diabetic groups at rest, 100 and 120 (beats per $\min$ ) (a, c); $p<0.05$ diabetes vs non-diabetes groups at 100 and 120 (beats per minute) (a-d); $p<0.01$ type 1 diabetes vs all other groups at rest, 100 and 120 (beats per minute) (a, c); $p<0.01$ obese vs all other groups at 120 (beats per minute) (a, c). Data are mean $\pm \mathrm{SE}$ type 2 diabetic groups than in the non-diabetic groups $(p<$ 0.001 and $p<0.01$ respectively). The changes in $\mathrm{CO}_{\text {ffm }}$ and $\mathrm{SV}_{\mathrm{ffm}}$ responses to exercise in the diabetic groups were similar ( $p=0.5$ and 0.6 respectively). The $\mathrm{a}-\mathrm{vO}_{2}$ was not different between groups in all conditions $(p=0.3)$. Analyses did not find any evidence that diabetes duration or $\mathrm{HbA}_{1 \mathrm{c}}$ were associated with the reductions in $\mathrm{CO}_{\text {ffm }}$ and $\mathrm{SV}_{\text {ffm. }}$. Body fat percentage was associated with lower maximal heart rate $(p=$ $0.028)$, higher cardiac output $(1 / \mathrm{min} ; p<0.001)$ and larger stroke volume $(\mathrm{ml} ; p<0.001)$.

\section{Discussion}

This study demonstrates that female adolescents with type 2 and type 1 diabetes mellitus have reduced aerobic capacity and blunted stroke volume responses to submaximal exercise compared with non-diabetic controls. Furthermore, girls with type 2 diabetes mellitus have a lower aerobic capacity and maximal heart rate than girls with type 1 diabetes mellitus. These findings suggest that cardiac impairment occurs early in the progression of diabetic complications.

The main finding of this study is that stroke volume was lower during submaximal exercise in type 2 and 1 diabetic adolescents. While the data from this study do not elucidate the mechanisms involved, diabetes-related cardiovascular characteristics may explain the lower exercising stroke volume in diabetic patients. Prolonged hyperglycaemia alters myocardial structure through the accumulation of advanced glycation end-products and, in the case of collagen, by promoting fibrosis and decreased connective tissue flexibility [6]. Because the increment in stroke volume during upright exercise is caused primarily by increases in end-diastolic volume [7], increased myocardial stiffness and/or altered filling characteristics might limit the exercise.

Maximal heart rate was lower in type 2 diabetic female adolescents than in other groups. Because the respiratory exchange ratio was greater than 1.05 in all groups and all but one type 2 diabetic participant had a plateau in $\dot{V} \mathrm{O}_{2}$ (increase of $<250 \mathrm{ml}$ in $\dot{V} \mathrm{O}_{2}$ with increase in workload) during maximal test, we do not believe this represented an inability to achieve the true maximum. An alternative explanation is that autonomic dysfunction, which appears in diabetic adults [8], occurs in type 2 diabetic adolescents. Autonomic neuropathy has been described early after the diagnosis of type 2 diabetes [4] and reduced maximal heart rate has been reported in type 2 diabetic adults [9]. Of particular interest, type 2 diabetic female adolescents may have lower heart rate variability than type 1 diabetic adolescents [4]. In this context, we believe our finding of lower peak heart rate indicates that type 2 diabetic adolescents, like their adult counterparts, may have an impaired autonomic response to exercise. However, further investigation is needed to clarify 
the causes of the lower peak heart rate in type 2 diabetic adolescents.

The $\mathrm{a}-\mathrm{vO}_{2}$, calculated using the Fick equation and measured cardiac output and oxygen uptake, is lower during exercise in adult type 2 diabetic patients [5], but not in diabetic adolescents. Baldi et al. [5] found that $\mathrm{a}-\mathrm{vO}_{2}$ was lower during exercise in type 2 diabetic adults and postulated that impaired endothelial function may have effected a maldistribution of blood to exercising muscle. In contrast, we found that $\mathrm{a}-\mathrm{vO}_{2}$ was the same in diabetic as in non-diabetic adolescents. Further investigations are needed to clarify the contribution of peripheral function to the decreased aerobic capacity of diabetic adolescents, since impaired endothelial function has already been observed in this population [10].

This is a relatively small study and the results should be viewed as preliminary data. However, they demonstrate abnormalities in cardiac function that impair $\dot{V} \mathrm{O}_{2}$ at a relatively early stage in the absence of clinically overt microvascular or macrovascular disease.

In conclusion, adolescent type 1 and 2 diabetic female patients have decreased aerobic capacity and a blunted stroke volume response to submaximal exercise compared with non-diabetic adolescents. Type 2 diabetic adolescents may also have an impaired autonomic response to exercise, limiting their peak heart rate and further limiting aerobic capacity. It remains unclear whether these changes can be attenuated or reversed by improving metabolic control or exercise training.

Acknowledgements This study was supported in part by a research grant from SPARC (Sport and Recreation New Zealand).
Duality of interest The authors declare that there is no duality of interest associated with this manuscript.

\section{References}

1. Pinhas-Hamiel O, Dolan LM, Daniels SR, Standiford D, Khoury PR, Zeitler P (1996) Increased incidence of non-insulin-dependent diabetes mellitus among adolescents. J Pediatr 128:608-615

2. Loimaala A, Groundstroem K, Majahalme S, Nenonen A, Vuori I (2006) Impaired myocardial function in newly onset type 2 diabetes associates with arterial stiffness. Eur J Echocardiogr 7:341-347

3. Nadeau K, Ehlers L, Zeitler B, Draznin B, Regensteiner JG, Reusch JE (2007) Exercise capacity is abnormal in youth with type 2 diabetes. J Investig Med 55:S76

4. Faulkner MS, Quinn L, Rimmer JH, Rich BH (2005) Cardiovascular endurance and heart rate variability in adolescents with type 1 or type 2 diabetes. Biol Res Nurs 7:16-29

5. Baldi JC, Aoina JL, Oxenham HC, Bagg W, Doughty RN (2003) Reduced exercise arteriovenous $\mathrm{O}_{2}$ difference in type 2 diabetes. $\mathrm{J}$ Appl Physiol 94:1033-1038

6. Cooper ME (2004) Importance of advanced glycation end products in diabetes-associated cardiovascular and renal disease. Am J Hypertens 17:31S-38S

7. Poliner LR, Dehmer GJ, Lewis SE, Parkey RW, Blomqvist CG, Willerson JT (1980) Left ventricular performance in normal subjects: a comparison of the responses to exercise in the upright and supine positions. Circulation 62:528-534

8. Poirier P, Bogaty P, Philippon F, Garneau C, Fortin C, Dumesnil JG (2003) Preclinical diabetic cardiomyopathy: relation of left ventricular diastolic dysfunction to cardiac autonomic neuropathy in men with uncomplicated well-controlled type 2 diabetes. Metabolism 52:1056-1061

9. Fang ZY, Sharman J, Prins JB, Marwick TH (2005) Determinants of exercise capacity in patients with type 2 diabetes. Diabetes Care 28:1643-1648

10. Pichler G, Urlesberger B, Jirak P et al (2004) Reduced forearm blood flow in children and adolescents with type 1 diabetes (measured by near-infrared spectroscopy). Diabetes Care 27:1942-1946 